\title{
Relationship of hospital size, case volume, and cost for coronary artery bypass surgery: Analysis of 12,774 patients operated on in Massachusetts during fiscal years 1995 and 1996
}

David M. Shahian, MD

Gerald J. Heatley, MS

George A. Westcott, MSHPM

See related article on page 6 .
From the Departments of Thoracic and Cardiovascular Surgery, Research, and Planning, Lahey Clinic Medical Center, Burlington, Mass.

Read at the Eightieth Annual Meeting of The American Association for Thoracic Surgery, Toronto, Ontario, Canada, April 30-May 3, 2000 .

Received for publication May 4, 2000; revisions requested Sept 14, 2000; revisions received Dec 19, 2000; accepted for publication Dec 20, 2000

Address for reprints: David M. Shahian, MD, Department of Thoracic and Cardiovascular Surgery, Lahey Clinic Medical Center, 41 Mall Rd, Burlington, MA 01805 (E-mail: David.M.Shahian@Lahey.ORG).

J Thorac Cardiovasc Surg 2001;122:53-64

Copyright (C) 2001 by The American Association for Thoracic Surgery

0022-5223/2001 $\$ 35.00+0 \quad \mathbf{1 2 / 6 / 1 1 3 7 5 0}$

doi: $10.1067 / \mathrm{mtc} .2001 .113750$
Objective: This study investigates the relationship between the cost of coronary artery bypass graft surgery and both hospital size and case volume.

Methods: Retrospective administrative and cost data were obtained for all 12,774 patients who underwent isolated coronary bypass surgery at 12 Massachusetts hospitals during 1995 and 1996. Hospitals were stratified by number of operating beds into 3 groups (group I, <250 beds; group II, 250-450 beds; group III, >450 beds). Total (diagnosis-related groups $106+107$ ) annual coronary bypass cases per hospital varied from 271 to 913 (mean 532). Univariate and multivariable analyses were used to study the relationship between the direct and total cost and a number of patient (age, sex, acuity class, payer) and hospital (bed capacity, annual case volume per diagnosis-related group, cardiothoracic residency) predictor variables. For each hospital, we also studied the relationship between changes in coronary bypass case volume and the corresponding changes in average cost from 1995 to 1996.

Results: Scatterplots revealed a broad range of mean direct cost of coronary bypass surgery among hospitals with comparable case volumes. When annual cases were analyzed as continuous variables, there was no linear relationship of case volume with direct or total cost of coronary bypass $(r=-0.05$ to +0.08$)$ for any diagnosisrelated group or year. When hospital bed capacity and case volume were grouped into strata and studied by analysis of variance, there was no evidence of an inverse relationship between these variables and cost. In multivariable analysis, patient acuity class and diagnosis-related group were the most important predictors of cost. Beds and case volume met inclusion criteria for most models but added little to the "explanation" of variability $R^{2}$, often less than $1 \%$. Finally, substantial interhospital differences were noted in the magnitude and direction (direct vs inverse) of their 1995 to 1996 change in volume versus change in cost.

Conclusions: Within the range of hospital size and case volume represented in this study, there is no evidence that either variable is related to the cost of performing coronary bypass surgery. Massachusetts hospitals appear to function on different segments of different average cost curves. It is not possible to predict the relative cost of coronary bypass grafting at a given hospital based primarily on volume.

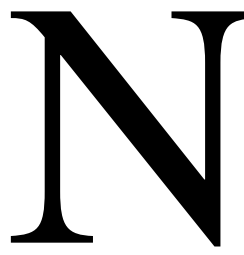

umerous factors have been postulated to influence the clinical outcome and cost of coronary artery bypass graft surgery (CABG). These include preoperative clinical status (age, sex, race, left ventricular dysfunction, reoperative or emergency surgery, diabetes, renal failure, chronic obstructive pulmonary disease), surgeon, postoperative morbidity and mortality, hospital 
case volume, geographic location, the presence of a residency teaching program, and payer. ${ }^{1-13}$ Institution or program case volume (and often, by implication, hospital size) is widely believed to be inversely related to both mortality ("practice makes perfect") and cost ("economies of scale").

The link between hospital volume and clinical outcome has been studied extensively ${ }^{11,14,15}$ since the pioneering work of Luft, Bunker, and Enthoven ${ }^{15}$ more than two decades ago. Because surgical procedures, especially CABG, have well-defined morbidity and mortality end points, they have been the major focus of such research. On the basis of its presumed relationship to quality, volume has been used as a criterion for referral and as a minimum licensing threshold for hospitals and physicians. ${ }^{16}$ It has also been used as a basis for preferential government and private contracts. However, questions have recently emerged regarding this putative relationship. Some have speculated that program volume and quality may appear related not because "practice makes perfect" but because of "selective referral" to historically high quality hospitals, ${ }^{16}$ which tends to reinforce and perpetuate their reputation. Recent reviews from The Society of Thoracic Surgeons, ${ }^{17}$ the Veterans Affairs hospital system, ${ }^{18}$ and an independent meta-analysis ${ }^{19}$ have also demonstrated that higher mortality rates occur primarily in very low volume programs $(<100$ cases per year). The results of such studies are dependent on the degree to which the data are adjusted for case-mix and time period, ${ }^{19}$ with more recent data showing less significant relationship between volume and mortality. ${ }^{19,20}$ The previously demonstrated inverse relationship between individual surgeon volume and operative mortality in New York was no longer statistically significant in more recent reports. ${ }^{21}$ In a similar but independent study of 97,137 CABGs performed in New York between 1990 and 1995, there was also no observed volumemortality relationship. ${ }^{20}$ Hannan $^{16}$ speculates that quality initiatives may mitigate the effect of volume. Overall, there appears to be a growing realization that volume criteria are both crude and arbitrary, useful mainly as a first iteration only if other data are unavailable. ${ }^{22}$ Objective measures of actual surgeon performance and hospital process should be used whenever possible.

The corollary relationship of cost to case volume, accepted by many as proven fact, is based on even more problematic and dated empiric studies. It is assumed by many insurers, government officials, and health planners that larger programs perform $\mathrm{CABG}$ procedures more cost effectively, primarily because their fixed costs are distributed over more patients. Interestingly, this "economies of scale" hypothesis has not been tested in a multi-institutional study encompassing a broad range of program size and payers and using modern data. A report by Cowper and associates ${ }^{1}$ using 1990 Medicare data identified hospital volume as a multivariable but not univariate cost predictor. However, only
Medicare patients were studied, the amount of cost variation explained by volume is not specified, and the hospitals were in diverse geographic regions. The revised 1996 American College of Surgeons Guidelines for Standards in Cardiac Surgery ${ }^{23}$ recommended 200 or more cases per program per year for "efficient" functioning but provided no supporting data. The American College of Cardiology/American Heart Association guidelines for $\mathrm{CABG}^{4}$ cited the work of McGregor and Pelletier, ${ }^{8}$ Showstack and associates, ${ }^{9}$ and Finkler $^{24}$ regarding the inverse relationship between outcome (cost and length of stay) and volume, specifically the decrease in cost that appears to occur above program volumes of $100^{8}$ or $300^{24}$ cases per year. However, these studies are based on data from the 1970s and 1980s, and they do not necessarily reflect current experience.

Finally, simplistic volume-cost hypotheses often fail to acknowledge the potential interhospital variability of production functions and average cost curves. It is impossible to understand the economics of CABG within a given market, including the relationship of volume to cost, without considering such confounding factors.

The object of this study was to investigate the relationship of hospital size and case volume to the cost of providing a CABG procedure in Massachusetts during fiscal years 1995 and 1996. Although a small state, Massachusetts has a broad range of hospital size, cardiac case volume, and academic involvement, a well-defined market area, and regulatory requirements that mandate the reporting of basic cost and outcome data.

We attempt to answer some basic questions raised by the "economies of scale" argument. Is "bigger" usually "better" with regard to CABG cost efficiency? Should government or private insurers who seek the lowest cost $\mathrm{CABG}$ provider always look first to the largest program? From the relative CABG volume at two hospitals, can one predict their relative costs? Will a hospital inevitably decrease its average cost per procedure by increasing its volume?

\section{Methods}

Anonymous patient level data were available from HealthShare Technology, Inc (Acton, Mass) for each of the 12,774 patients who underwent isolated CABG (diagnosis-related group [DRG] 106107) at 12 Massachusetts institutions during fiscal years 1995 and 1996. One Veterans Affairs hospital was excluded.

Statistical analyses were performed with SAS Statistical Software (release 6.1, SAS Institute, Inc, Cary, NC) and PASS power analysis software (NCSS Statistical Software, Kaysville, Utah). We performed one analysis of the entire group of 12,774 patients in which DRG and fiscal year were used as predictor variables. We also analyzed each DRG and fiscal year (FY) subgroup (DRG 106-FY 95, DRG 106-FY 96, DRG 107-FY 95, DRG 107-FY 96) separately because of the substantial cost differences between DRGs 106 and 107 for each year $(P<.0001)$ and between fiscal years 1995 and 1996 for each DRG $(P<.0001)$. 


\section{Cases vs Average Direct Cost}

$106-95$

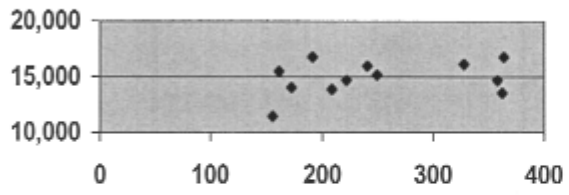

$107-95$

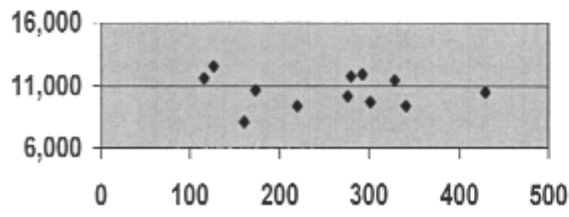

$106-96$

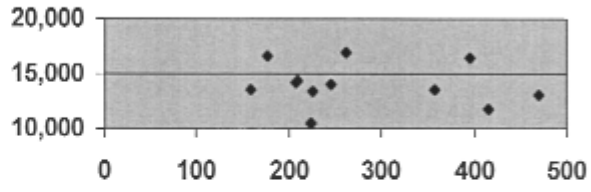

$107-96$

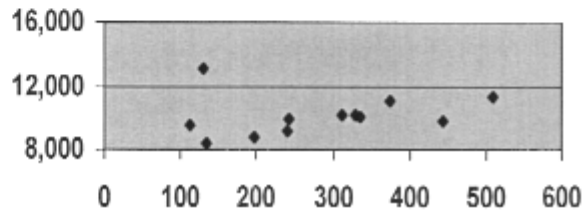

Figure 1. Scatterplots of average direct cost versus case volume for each hospital by DRG and year.

Six separate analyses were performed: (1) Scatterplots were initially used to explore the relationship between hospital case volume and direct cost. (2) The univariate relationship between cost and multiple predictor variables was examined. Case volume was analyzed as a continuous variable, with the use of individual patient cost data and the case volume of the hospital at which that patient had surgery. (3) Analysis of variance was used to study the relationship between costs and strata of bed capacity and case volume. Both the overall $P$ value and the Scheffé test for significant pairwise comparisons were determined. (4) Multivariable analysis was performed with log direct or total cost as the dependent variables. Direct cost represents the resource use directly attributable to the CABG procedure. This is probably the most valid for comparative purposes, because methods of overhead allocation vary among hospitals. Forward stepwise selection was used, with $P$ value $<.15$ necessary for inclusion in the model. A similar multivariable analysis was also performed using length of stay as an alternative, process-related end point. (5) Cox proportional hazards model was used, substituting direct cost for survival to eliminate concern regarding the assumptions of traditional multiple regression models. Patients who died in the hospital were censored at time of death because they would have continued to generate cost had they survived. ${ }^{25,26}$ The proportional hazard assumption was tested graphically with log-log curves for each significant variable. (6) Finally, the percent change in DRG-specific case volume for each hospital from 1995 to 1996 was determined and compared with the corresponding changes in cost to see whether any consistent relationship was present. A similar approach, using sequential outcome data from individual hospitals as they increase or decrease their volume, has been suggested as the most definitive way to test the volume-quality relationship. ${ }^{16}$

For each patient, a number of predictor variables were available, including those relating to the patient (clinical acuity class [refined $\mathrm{DRG}^{27}$ ], age, sex), the hospital at which the operation was performed (bed capacity, annual DRG-specific case volume, presence of an approved cardiothoracic residency training program), and the payer. Hospital bed capacity was based on the best available 1995 and 1996 data, and this information was used to group the hospitals into 3 strata for analysis (group I, $<250$ beds, group II, 250-450 beds; and group III, $>450$ beds). Data from each distinct hospital entity were analyzed separately although several institutions had undergone corporate integration during the period of the study. Outcome measures (eg, mortality and length of stay) were not included as predictor variables. These are highly correlated with cost and would have dramatically increased the $R^{2}$ of the models, but they would also have decreased our ability to determine the relative importance of other variables in which we were specifically interested.

Charge data for each patient were obtained from the Massachusetts Division of Health Care Finance and Policy. These were converted to costs by means of the cost center-specific ratios of costs to charges (RCC) derived from the Medicare Cost Report (form 2552). This is a generally accepted and validated method whose results are accurate to within $10 \% .^{28}$ The 1995 RCC was used for both 1995 and 1996 data, because the 1996 RCC was unavailable at the time of the analysis. Differences between RCCs for successive years are generally small, and this is a close and commonly used approximation (personal communication, Richard Siegrist, Jr, president and chief executive officer, HealthShare Technology, Inc, Acton, Mass).

Direct costs included both the fixed and variable components of costs directly attributable to patient care. Total costs included direct costs, hospital overhead allocation, and medical education costs.

\section{Results}

Of the 12 hospitals in the study, three were in bed group I in both 1995 and 1996, and one hospital moved from group II in 1995 to group I in 1996. Five hospitals were in group II and three hospitals were in group III during both years. Total (DRGs $106+107$ ) annual CABG volume averaged 532 cases (range 271-913) during fiscal year 1995-1996. 
TABLE 1. Univariate statistics

\begin{tabular}{|c|c|c|c|c|c|c|c|c|}
\hline & \multicolumn{4}{|c|}{ DRG 106-FY 95} & \multicolumn{4}{|c|}{ DRG 106-FY 96} \\
\hline & No. & $\%$ & Direct cost & Total cost & No. & $\%$ & Direct cost & Total cost \\
\hline All patients & 3,018 & 100.0 & 15,021 & 29,288 & 3,347 & 100.0 & 13,949 & 27,303 \\
\hline \multicolumn{9}{|l|}{ Residency } \\
\hline No & 1,291 & 42.8 & 14,700 & 29,744 & 1,391 & 41.6 & 13,145 & 26,958 \\
\hline Yes & 1,727 & 57.2 & 15,260 & 28,947 & 1,956 & 58.4 & 14,521 & 27,549 \\
\hline$P=$ & & & .0444 & .1502 & & & .0001 & .1903 \\
\hline \multicolumn{9}{|l|}{ Payer } \\
\hline Blue Cross & 242 & 8.0 & 13,788 & 27,304 & 260 & 7.8 & 12,362 & 24,196 \\
\hline HMO & 566 & 18.8 & 13,203 & 25,637 & 686 & 20.5 & 12,726 & 24,801 \\
\hline Medicare & 1,787 & 59.2 & 15,916 & 30,991 & 1,889 & 56.4 & 14,632 & 28,650 \\
\hline Commercial & 204 & 6.8 & 13,652 & 26,342 & 225 & 6.7 & 13,462 & 26,310 \\
\hline$P=$ & & & .0001 & .0001 & & & .0001 & .0001 \\
\hline \multicolumn{9}{|l|}{ Sex } \\
\hline$M$ & 2,090 & 69.3 & 14,566 & 28,487 & 2,294 & 68.5 & 12,595 & 26,595 \\
\hline $\mathrm{F}$ & 928 & 30.7 & 16,044 & 31,092 & 1,053 & 31.5 & 14,721 & 28,846 \\
\hline$P=$ & & & .0001 & .0001 & & & .0001 & .0001 \\
\hline \multicolumn{9}{|l|}{ Refined DRG } \\
\hline Class 0 & 73 & 2.4 & 11,444 & 22,689 & 56 & 1.7 & 10,674 & 21,391 \\
\hline Class 1 & 560 & 18.6 & 11,224 & 22,338 & 684 & 20.4 & 10,840 & 21,548 \\
\hline Class 2 & 1,428 & 47.3 & 13,494 & 26,142 & 1,586 & 47.4 & 12,762 & 24,984 \\
\hline Class 3 & 957 & 31.7 & 19,794 & 38,553 & 1,021 & 30.5 & 18,056 & 35,087 \\
\hline$P=$ & & & .0001 & .0001 & & & .0001 & .0001 \\
\hline
\end{tabular}

$D R G$, Diagnosis-related group; $F Y$, fiscal year; $H M O$, health maintenance organization.

Figure 1 depicts scatterplots of hospital volume versus average direct cost for each DRG and fiscal year. Hospitals with similar case volume had widely disparate average costs, and there was no linear relationship between costs and volume. These observations support our belief that the volume-cost relationship within the Massachusetts market area cannot be described by a single average cost curve.

The remainder of the analyses were performed with disaggregate, patient-specific data. Univariate statistics for each DRG and year are presented in Table 1. Medicare insurance, female sex, and higher refined DRG class were associated with higher direct and total costs. A cardiothoracic residency program was associated with higher direct costs. Continuous variables were analyzed by means of the Pearson correlation coefficient. There was no linear relationship between case volume and either direct or total cost ( $r=-0.05$ to 0.08$)$. Age was similarly unrelated to cost ( $r=0.13$ to 0.15 ).

Table 2 presents an analysis of cost versus 3 strata of hospital bed size using analysis of variance. A similar analysis of cost versus strata of case volume is shown in Table 3 . There is no evidence of an inverse relationship between costs and either hospital size or program volume.

Multivariable model results for the entire sample of 12,774 patients are presented in Tables 4 (direct cost) and 5 (total cost). Table 6 presents a similar analysis using length of stay as an alternative end point. Other than DRG group, acuity class was consistently the most important predictor in all models. Case volume and hospital beds met entry criteria for most of the models but added little, often a fraction of $1 \%$, to the "explanation" of cost variability $R^{2}$. Subgroup models for each DRG and year produced similar results, and these are available on request from us. Power analysis was performed for all multiple regression models. In all cases, power exceeded 0.90 at $\alpha .05$.

The proportional hazards assumption of the Cox model was violated by the observed data, and consequently this model was not used.

As depicted in Figure 2, $A$ and $B$, there was no consistent relationship between the percent change in case volume for a given hospital during the fiscal years 1995 and 1996 and its corresponding percent change in direct cost. The relationship between the changes in the two variables was direct for some hospitals and inverse for others, and the magnitude of change in cost for a given change in volume varied greatly. These findings suggest that hospitals are functioning on different portions of their respective cost curves.

\section{Discussion}

The putative inverse relationship between CABG volume and mortality ("practice makes perfect") has been re-evaluated in recent years and appears to be a valid concern only for very low volume programs. ${ }^{17-21}$ Accumulated CABG 


\begin{tabular}{|c|c|c|c|c|c|c|c|}
\hline \multicolumn{4}{|c|}{ DRG 107-FY 95} & \multicolumn{4}{|c|}{ DRG 107-FY 96} \\
\hline No. & $\%$ & Direct cost & Total cost & No. & $\%$ & Direct cost & Total cost \\
\hline 3,049 & 100.0 & 10,516 & 20,230 & 3,360 & 100.0 & 10,206 & 19,676 \\
\hline 1,100 & 36.1 & 10,056 & 19,886 & 1,146 & 34.1 & 9,752 & 19,554 \\
\hline \multirow[t]{2}{*}{1,949} & 63.9 & 10,776 & 20,424 & 2,214 & 65.9 & 10,441 & 19,740 \\
\hline & & .0038 & .2497 & & & .0002 & .6031 \\
\hline 258 & 8.5 & 10,399 & 20,399 & 269 & 8.0 & 9,496 & 18,417 \\
\hline 620 & 20.3 & 9,326 & 17,638 & 803 & 23.9 & 9,442 & 17,961 \\
\hline 1,705 & 55.9 & 11,204 & 21,603 & 1,750 & 52.1 & 10,872 & 21,032 \\
\hline \multirow[t]{2}{*}{249} & 8.2 & 9,235 & 17,702 & 232 & 6.9 & 9,480 & 18,416 \\
\hline & & .0001 & .0001 & & & .0001 & .0001 \\
\hline 2,290 & 75.1 & 10,371 & 19,893 & 2,536 & 75.5 & 10,039 & 19,417 \\
\hline \multirow[t]{2}{*}{759} & 24.9 & 10,954 & 21,247 & 824 & 24.5 & 10,721 & 20,476 \\
\hline & & .0350 & .0091 & & & .0008 & .0070 \\
\hline 242 & 7.9 & 8,285 & 16,028 & 191 & 5.7 & 8,434 & 16,136 \\
\hline 778 & 25.5 & 8,579 & 16,733 & 914 & 27.2 & 8,423 & 16,333 \\
\hline 1,411 & 46.3 & 9,971 & 19,092 & 1,565 & 46.6 & 9,778 & 18,834 \\
\hline \multirow[t]{2}{*}{618} & 20.3 & 15,073 & 28,874 & 690 & 20.5 & 14,028 & 26,996 \\
\hline & & .0001 & .0001 & & & .0001 & .0001 \\
\hline
\end{tabular}

experience, better trained surgeons, improved medical stabilization, standardized protocols, better myocardial protection and perfusion techniques, and other advancements have permitted sicker patients to be operated on with significantly improved clinical outcomes and cost efficiency. ${ }^{29-32}$

The relationship of CABG volume to cost is another firmly entrenched yet unsubstantiated belief. Most CABG cost studies are single institutional and, with the exception of the work of Denton, Luevanos, and Matloff, ${ }^{7}$ have focused primarily on clinical predictors. They have demonstrated limited ability to predict cost $\left(R^{2}=0.22-0.29\right),{ }^{13,33,34}$ as did the only multi-institutional study by Cowper and associates ${ }^{1}\left(R^{2}=0.25\right)$. The relationship of cost, hospital size, and case volume has not been analyzed in a modern, multi-institutional study encompassing both Medicare and non-Medicare patients.

To eliminate known geographic differences in cost, our study focused on a single state with a substantial diversity of programs. Massachusetts has a representative mix of hospitals with regard to size, case volume, cardiothoracic residency programs, and payer distribution. Because of statemandated reporting, we were able to acquire basic clinical and economic data for each patient and to test the significance of multiple factors on cost.

Despite the use of multiple different statistical techniques and both aggregate and disaggregate data, we were unable to show any consistent relationship between cost and either hospital beds or case volume. These results appear counterintuitive to the concept of "economies of scale" and conflict with widely held beliefs. We believe our data suggest two explanations. First, it is a fundamental misconception to assume that the CABG production functions and average cost curves of hospitals within a given market are homogeneous. Only in this situation would a single, simplistic volume-cost relationship be expected. It is essential to distinguish between (1) movement along a single hospital's average cost curve (Figure 3 ) as volume changes and (2) the family of cost curves from different hospitals within a market sector (Figure 4). The latter may vary in position, slope, or shape, thus yielding different costs at any given volume level. For a single hospital (see Figure 3), the average unit cost typically decreases as volume increases because of the distribution of fixed costs over a larger number of cases. ${ }^{35,36}$ At some point, a plateau is reached at which marginal cost equals the average cost. For some hospitals, this plateau portion is relatively broad, ${ }^{8,24,36}$ representing a range of excess capacity over which volume has little impact on average cost of a procedure (eg, in Figure 2, $A$ and $B$, hospitals D, G, and L had substantial 1995-1996 percent changes in volume with little change in direct cost). Occasionally, rapid expansion of CABG volume may exceed hospital resource capacity, leading to "bottleneck" and opportunity costs. This may result in an upturn in the average cost curve. 
TABLE 2. Hospital beds versus cost

\begin{tabular}{|c|c|c|c|c|c|c|c|c|}
\hline Group & Beds & Patients & Total cost & SD & $P$ value & Direct cost & SD & $P$ value \\
\hline \multicolumn{9}{|c|}{ DRG 106-FY 95} \\
\hline 1 & $<250$ & 615 & 26,011 & 10,778 & & 13,799 & 6,073 & \\
\hline II & $250-450$ & 1,319 & 30,052 & 15,694 & $.0001^{*}$ & 15,607 & 7,576 & $.0001^{*}$ \\
\hline III & $>450$ & 1,084 & 30,218 & 16,074 & & 15,000 & 8,238 & \\
\hline \multicolumn{9}{|c|}{ DRG 106-FY 96} \\
\hline 1 & $<250$ & 1,033 & 25,604 & 10,463 & & 13,124 & 5,655 & \\
\hline II & $250-450$ & 1,032 & 28,420 & 15,870 & $.0001^{*}$ & 15,056 & 8,203 & $.0001 \dagger$ \\
\hline III & $>450$ & 1,282 & 27,773 & 11,769 & & 13,724 & 6,309 & \\
\hline \multicolumn{9}{|c|}{ DRG 107-FY 95} \\
\hline 1 & $<250$ & 738 & 18,202 & 7,728 & & 9,486 & 4,046 & \\
\hline II & $250-450$ & 1,366 & 21,373 & 14,888 & $.0001^{*}$ & 11,363 & 8,098 & $.0001 \dagger$ \\
\hline III & $>450$ & 945 & 20,161 & 11,133 & & 10,097 & 5,578 & \\
\hline \multicolumn{9}{|c|}{ DRG 107-FY 96} \\
\hline 1 & $<250$ & 1,018 & 19,382 & 8,990 & & 9,850 & 4,707 & \\
\hline ॥ & $250-450$ & 1,193 & 19,373 & 11,378 & .0487 & 10,477 & 5,636 & $.0143 \ddagger$ \\
\hline III & $>450$ & 1,149 & 20,253 & 8,622 & & 10,240 & 4,706 & \\
\hline
\end{tabular}

$S D$, Standard deviation; $D R G$, diagnosis-related group; $F Y$, fiscal year; $P=$ Overall analysis of variance; significant Scheffé test comparisons: *I versus II and III; †II versus I and III; †I versus II.

TABLE 3. Hospital cases versus cost

\begin{tabular}{|c|c|c|c|c|c|c|c|c|}
\hline Group & Cases & Patients & Total cost & SD & $P$ value & Direct cost & SD & $P$ value \\
\hline \multicolumn{9}{|c|}{ DRG 106-FY 95} \\
\hline I & $<200$ & 683 & 29,753 & 16,562 & & 14,558 & 6,948 & \\
\hline ॥ & $200-350$ & 1,251 & 28,229 & 13,106 & $.0041^{*}$ & 15,291 & 7,294 & .1258 \\
\hline III & $>350$ & 1,084 & 30,218 & 16,074 & & 15,000 & 8,238 & \\
\hline \multicolumn{9}{|c|}{ DRG 106-FY 96} \\
\hline I & $<200$ & 335 & 31,716 & 16,589 & & 15,201 & 6,744 & \\
\hline II & $200-350$ & 1,372 & 25,740 & 12,874 & $.0001^{*} \dagger$ & 13,973 & 7,382 & $.0009 \dagger$ \\
\hline III & $>350$ & 1,640 & 27,710 & 11,727 & & 13,674 & 6,290 & \\
\hline \multicolumn{9}{|c|}{ DRG 107-FY 95} \\
\hline I & $<200$ & 577 & 22,061 & 13,375 & & 10,516 & 5,830 & \\
\hline II & $200-350$ & 2,043 & 19,924 & 12,773 & $.0002 \dagger$ & 10,523 & 7,112 & .9937 \\
\hline III & $>350$ & 429 & 19,223 & 8,320 & & 10,484 & 4,842 & \\
\hline \multicolumn{9}{|c|}{ DRG 107-FY 96} \\
\hline I & $<200$ & 576 & 20,817 & 13,642 & & 9,768 & 5,803 & \\
\hline II & $200-350$ & 1,459 & 18,957 & 8,590 & $.0002 \ddagger$ & 9,926 & 4,650 & $.0001 * \S$ \\
\hline III & $>350$ & 1,325 & 19,973 & 8,958 & & 10,704 & 5,112 & \\
\hline
\end{tabular}

$S D$, Standard deviation; $D R G$, diagnosis-related group; $F Y$, fiscal year; $P=0$ verall analysis of variance; significant Scheffé test comparisons: ${ }^{*} I$ versus III; †I versus II and III; †II versus I and III; §I versus III.

This volume-cost relationship applies to a single hospital. It appears, however, that the cardiac programs in Massachusetts have different "production functions" for the CABG operation and thus different average cost curves. As demonstrated in the hypothetical example in Figure 4, one hospital (H2) may have a lower average cost curve than another (H1). Its cost is less for any given level of volume, and the volume required to achieve a given average cost per procedure is lower. It is thus impossible to predict the comparative cost of CABG at two hospitals simply from their respective volumes without knowing where this average cost curve lies relative to that of their competitors.
Furthermore, data in Figure 2, $A$ and $B$, suggest that hospitals are functioning at different points on their respective cost curves, and thus the impact of volume changes on each hospital's cost may differ greatly.

Like clinical outcome, CABG is a complex function of many factors other than just volume, and these collectively determine the position of a hospital's average cost curve. These factors include clinical case mix and acuity, quality control (decreasing the high costs associated with perioperative morbidity and mortality), standardized protocols, process efficiency, and practice patterns. ${ }^{37}$ They may result in a favorable shift of a hospital's average cost 


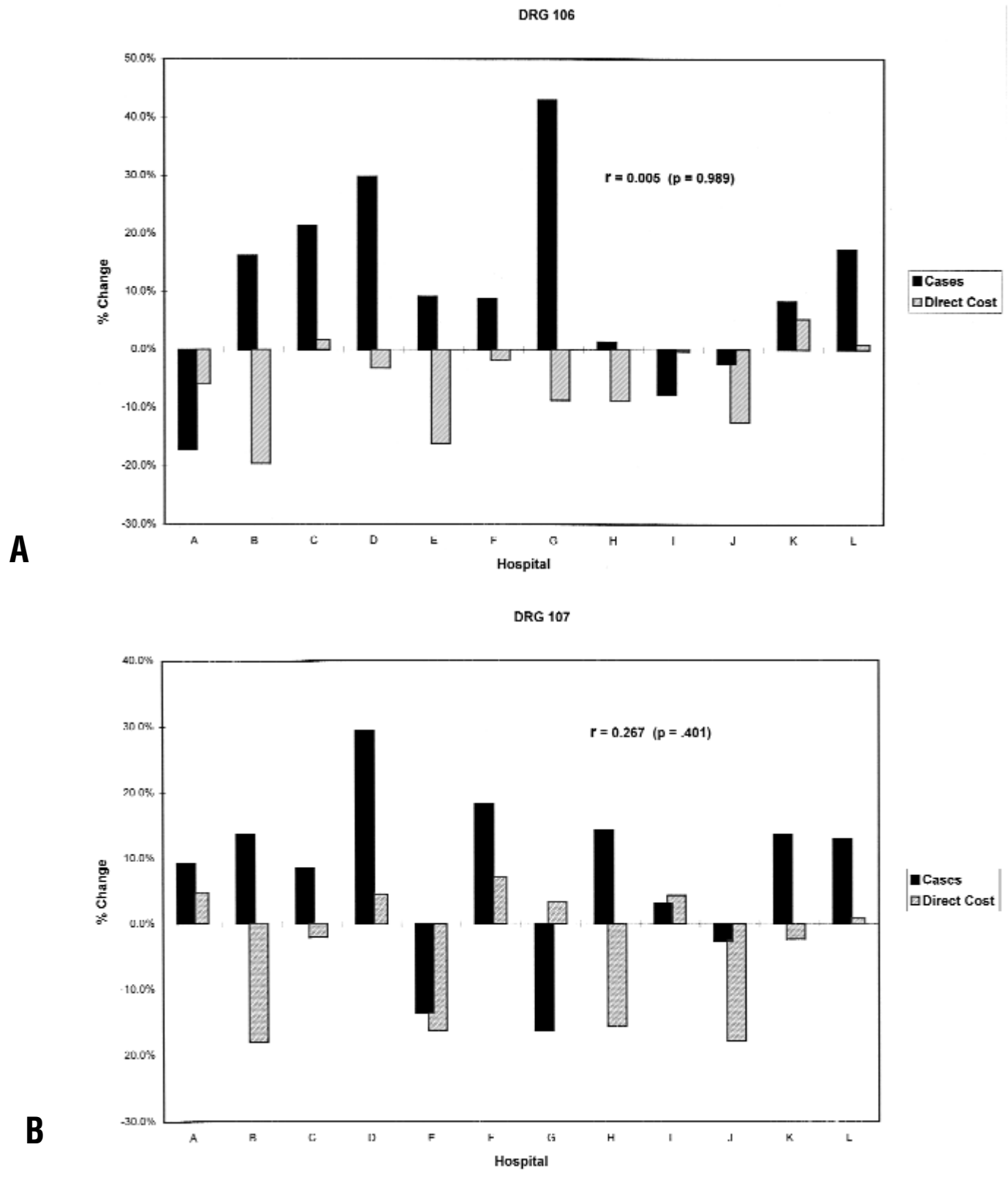

Figure 2. A, The percent change in case volume for each hospital between fiscal years 1995 and 1996 (DRG 106) is depicted in black bars along with the corresponding percent change in direct costs, depicted in gray hatched bars. There is no linear correlation between the changes observed for the two variables across the spectrum of 12 hospitals $(r=0.005)$. Both the magnitude and the direction of the relationship varied. In some instances, both variables increase; in others, both decrease. Only at 6 hospitals were the changes in the two variables inversely related. B, Similar data are plotted for DRG 107. Again, there is no linear relationship $(r=0.267)$, and for only 5 hospitals was the change in the two variables inversely related.

curve rather than simply relying on movement along that curve. Interhospital differences in such factors affect relative cost at all levels of volume. Furthermore, the opportunity for excellence in these areas is not a function of program size.

\section{Caveats}

Several potential concerns regarding our study must be addressed. First, accurate cost data for CABG is notoriously difficult to obtain, even at one's own hospital. However, the data used in our study were submitted to various state 
TABLE 4. Multivariable model for log direct cost

\begin{tabular}{|c|c|c|c|c|}
\hline Variable & Partial $R^{2}$ & Model $R^{2}$ & Parameter estimate & $P$ value \\
\hline Refined DRG class 3 & 0.1802 & 0.1802 & 0.4364 & .0001 \\
\hline DRG 107 & 0.1281 & 0.3084 & -0.2854 & .0001 \\
\hline Refined DRG class 2 & 0.0223 & 0.3306 & 0.1559 & .0001 \\
\hline Age & 0.0081 & 0.3387 & 0.0021 & .0001 \\
\hline Bed group II & 0.0070 & 0.3457 & 0.0739 & .0001 \\
\hline Resident & 0.0074 & 0.3531 & 0.0565 & .0001 \\
\hline FY 96 & 0.0018 & 0.3549 & -0.0392 & .0001 \\
\hline Sex & 0.0015 & 0.3564 & -0.0328 & .0001 \\
\hline Medicare & 0.0013 & 0.3577 & 0.0332 & .0001 \\
\hline Cases & 0.0004 & 0.3581 & 0.0002 & .0063 \\
\hline HMO & 0.0002 & 0.3583 & -0.0168 & .0611 \\
\hline Bed group III & 0.0002 & 0.3585 & -0.0170 & .0680 \\
\hline Refined DRG class 1 & 0.0001 & 0.3586 & 0.0229 & .1251 \\
\hline
\end{tabular}

$D R G$, Diagnosis-related group; $F Y$, fiscal year; $H M O$, health maintenance organization.

TABLE 5. Multivariable model for log total cost

\begin{tabular}{lcccc}
\hline Variable & Partial $\boldsymbol{R}^{\mathbf{2}}$ & Model $\boldsymbol{R}^{\mathbf{2}}$ & Parameter estimate & $\boldsymbol{P}$ value \\
\hline DRG 107 & 0.1795 & 0.1795 & -0.2900 & .0001 \\
Refined DRG class 3 & 0.1377 & 0.3172 & 0.4268 & .0001 \\
Refined DRG class 2 & 0.0178 & 0.3350 & 0.1419 & .0001 \\
Age & 0.0100 & 0.3450 & 0.0024 & .0001 \\
FY 96 & 0.0019 & 0.3469 & -0.0261 & .0001 \\
Bed group III & 0.0018 & 0.3487 & .0001 \\
HMO & 0.0014 & 0.3501 & -0.0271 & .0001 \\
Bed group II & 0.0013 & 0.3515 & .0001 \\
Sex & 0.0013 & 0.3527 & .0 .0323 & .0001 \\
Medicare & 0.0005 & 0.3533 & .0010 \\
Refined DRG class 1 & 0.0002 & 0.3534 & 0.0292 & .0777 \\
Resident & 0.0001 & 0.3536 & 0.0275 & .0903 \\
Cases & 0.0005 & 0.3541 & 0.0244 & .0018 \\
\hline
\end{tabular}

$D R G$, Diagnosis-related group; $F Y$, fiscal year; $H M O$, health maintenance organization.

and federal agencies by regulatory requirement, and they should represent each hospital's best estimate of its true costs. There are probably no more accurate multi-institutional cost data currently available.

The second caveat concerns our use of the refined DRG as a clinical acuity index. The refined $\mathrm{DRG}^{27}$ is more commonly used as a generic, severity adjustment index for administrative data. Objections to the use of this method to compare risk-adjusted mortality among hospitals have been discussed extensively by Iezzoni, ${ }^{38}$ Hannan and colleagues, ${ }^{39}$ and Hartz and Kuhn. ${ }^{40}$ Most important is the inability to distinguish between comorbidities and complications. The refined DRG performs relatively well predicting CABG mortality but does so because it captures most important clinical events and diagnoses, some of which are preterminal. ${ }^{41}$ This may permit the risk-adjusted results of a hospital with high complication rates to appear similar to those of another hospital treating patients with higher preoperative acuity. Our study uses the refined DRG as a measure of overall clinical acuity to assess the relative importance of clinical versus nonclinical cost predictors. No assumptions are made as to whether the acuity level resulted from preoperative comorbidities or postoperative complications, only that the hospitalization entailed a certain level of clinical complexity. Used in this context, we believe the refined DRG is an appropriate tool.

Third, without a cardiac surgery-specific risk adjustment algorithm in the Massachusetts administrative database, we cannot exclude the possibility that some institutions may have had higher costs because they attracted more critically ill patients. Although risk-adjusted cost data would clearly be preferable, such information is currently unavailable. In fact, we are unaware of any published, multi-institutional cost studies that have used such risk adjustment. Our Massachusetts data are comparable with those used for most regional and national cost studies. Ideally, large risk-adjusted databases such as that maintained by The Society of Thoracic Surgeons will someday include cost data. Only then will it be possible to 


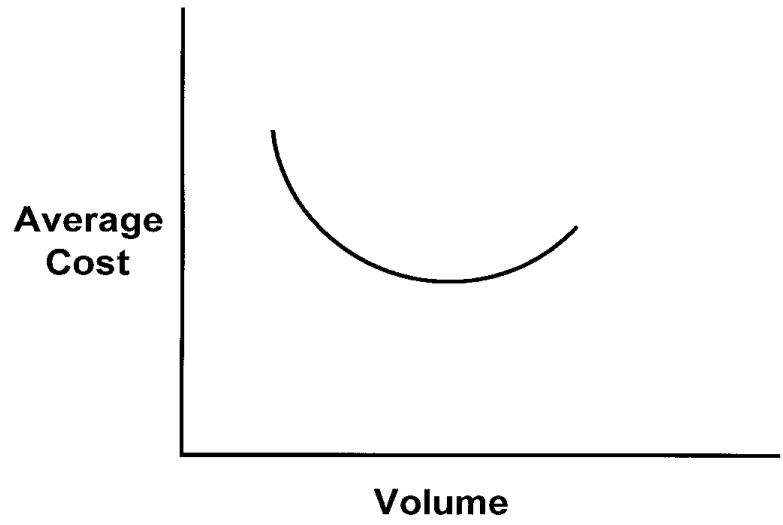

Figure 3. A typical average cost curve. Average cost falls as volume increases and as fixed costs are distributed over a larger number of procedures. This reaches a plateau, which may encompass a broad range of volume, over which average and marginal costs are equal, and volume does not significantly affect average cost. In the short term, significant volume expansion may exceed hospital resource capacity, and the resulting opportunity or bottleneck costs may increase average CABG cost.

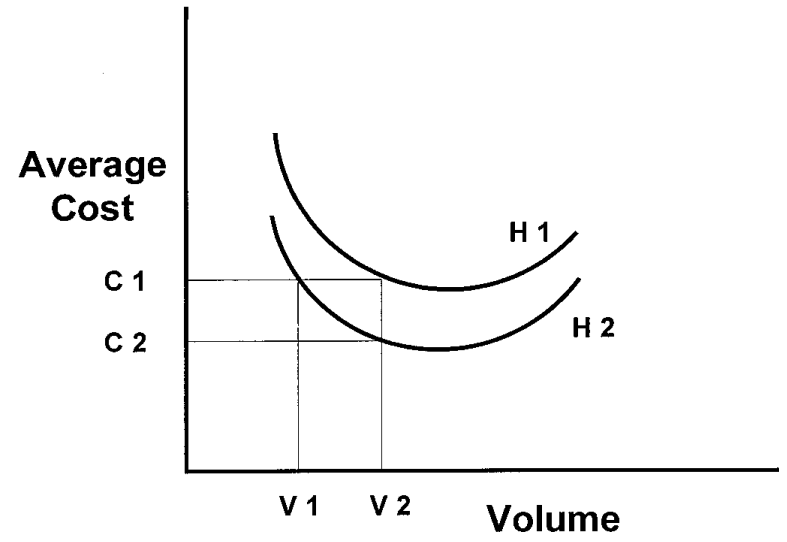

Figure 4. The hypothetical average cost curves for two hospitals (H1 and H2). Comparing two hospitals, the more efficient $\mathrm{H} 2$ will achieve a given level of cost (C1) at a significantly lower volume of cases (V1) than that required (V2) to achieve the same cost level at hospital H1. Conversely, at the same level of volume (V2), hospital H2 will have significantly lower costs (C2) than hospital H1 (C1).

TABLE 6. Multivariable model for length of stay

\begin{tabular}{lcccc}
\hline Variable & Partial $\boldsymbol{R}^{\mathbf{2}}$ & Model $\boldsymbol{R}^{\mathbf{2}}$ & Parameter estimate & $\boldsymbol{P}_{\text {value }}$ \\
\hline Refined DRG class 3 & 0.1425 & 0.1425 & 5.8165 & .0001 \\
DRG 107 & 0.0553 & 0.1978 & -2.7885 & .0001 \\
Age & 0.0165 & 0.2143 & 0.0473 & .0001 \\
Refined DRG class 2 & 0.0108 & 0.2250 & 1.5964 & .0001 \\
FY 96 & 0.0090 & 0.2340 & -1.2031 & .0001 \\
Bed group III & 0.0052 & 0.2392 & 1.0796 & .0001 \\
Sex & 0.0020 & 0.2411 & -0.6142 & .0001 \\
Medicare & 0.0011 & 0.2423 & 0.3531 & .0001 \\
HMO & 0.0003 & 0.2425 & -0.4293 & .0309 \\
Commercial & 0.0002 & 0.2427 & -0.3872 & .0714 \\
Bed group II & 0.0001 & 0.2429 & 0.1849 & .1407 \\
\hline
\end{tabular}

$D R G$, Diagnosis-related group; $F Y$, fiscal year; $H M O$, health maintenance organization.

compare the true risk-adjusted cost of cardiac procedures among programs.

As in most other studies of CABG costs, the ability of our multivariable model to explain variability in cost $\left(R^{2}\right)$ was limited. ${ }^{1,13,26,32-34}$ This suggests that other variables not in the model influence cost or that the relationships are nonlinear.

Only two successive yearly data points were available on each hospital's average cost curve. This is arguably a limited number of observations on which to base any broad inferences regarding the shape and location of these curves.

Finally, one should not extrapolate beyond the data set used to develop a predictive model. The lack of association of $\mathrm{CABG}$ cost with hospital size and case volume may not necessarily be observed in areas with very small programs or greater outcome variability. Our data do not answer the question as to whether there is a lower limit or "threshold" volume for a cost-efficient CABG program, because no such programs were available for our study. An inverse relationship might be observed at the very lowest limits of program size and conversely in those few very large programs that may enjoy true "economies of scale." However, our data encompass a broad range of hospital size and program volume that probably includes a majority of cardiac surgery units in the United States.

Our results are also most relevant to a procedure like traditional CABG that is "mature," having evolved over several decades. These procedures are frequently performed, and 
there are standard techniques for surgery, perfusion, and anesthesia. Our conclusions may not apply at an earlier stage of a procedure's evolution or to less frequently performed or standardized procedures. Finally, they cannot necessarily be extrapolated to other specialties.

\section{Conclusion}

Selection of a cardiac surgery provider should not be based on the simplistic expectation of lower costs at large or highvolume institutions. This is analogous to recent cautionary findings regarding the volume-mortality relationship. ${ }^{17-21}$ Despite the appeal of describing complex phenomena with simple models, such parsimony is rarely achievable. Like clinical outcome, cost is determined by a complex mix of factors. Cost reduction caused by movement along a hospital's average cost curve may not be as significant as superior process and quality control, which shift the entire curve to a more favorable level.

All hospitals should constantly strive to improve the process and quality of the CABG procedure. Health planners, insurers, corporations, and the government should focus on observed clinical and financial outcomes rather than on arbitrary volume standards. Small hospitals are fully capable of being cost competitive, and larger programs should not assume that volume alone will result in cost efficiency.

\section{References}

1. Cowper PA, DeLong ER, Peterson ED, Lipscomb J, Muhlbaier LH, Jollis JG, et al. Geographic variation in resource use for coronary artery bypass surgery. IHD Port Investigators. Med Care. 1997;35:320-3.

2. Hall RE, Ash AS, Ghali WA, Moskowitz MA. Hospital cost of complications associated with coronary artery bypass graft surgery. Am J Cardiol. 1997;79:1680-2.

3. Taylor GJ, Mikell FL, Moses HW, Dove JT, Katholi RE, Malik SA, et al. Determinants of hospital charges for coronary artery bypass surgery: the economic consequences of postoperative complications. Am J Cardiol. 1990;65:309-13.

4. Kirklin JW, Akins CW, Blackstone EH, et al. Guidelines and indications for coronary artery bypass graft surgery: a report of the American College of Cardiology/American Heart Association Task Force on Assessment of Diagnostic and Therapeutic Cardiovascular Procedures (Subcommittee on Coronary Artery Bypass Graft Surgery). J Am Coll Cardiol. 1991;17:543-89.

5. Starr A, Furnary AP, Grunkemeier GL, He GW, Ahmad A. Is referral source a risk factor for coronary surgery? Health maintenance organizations versus fee-for-service system. J Thorac Cardiovasc Surg. 1996;111:708-17.

6. Smith LR, Milano CA, Molter BS, Elbeery JR, Sabiston DC Jr, Smith PK. Preoperative determinants of postoperative costs associated with coronary artery bypass graft surgery. Circulation. 1994;90(Part 2):II124-8.

7. Denton TA, Luevanos J, Matloff JM. Clinical and nonclinical predictors of the cost of coronary bypass surgery: potential effects on health care delivery and reimbursement. Arch Intern Med. 1998;158:886-91.

8. McGregor M, Pelletier G. Planning of specialized health facilities: size vs. cost and effectiveness in heart surgery. $N$ Engl J Med. 1978;299:179-81.

9. Showstack JA, Rosenfeld KE, Garnick DW, Luft H, Schaffarzick RW, Fowles J. Association of volume with outcome of coronary artery bypass graft surgery: scheduled vs nonscheduled operations. JAMA 1987;257:785-9.

10. Parsonnet V, Bernstein AD. Outcome versus volume in coronarybypass operations. Ann Thorac Surg. 1996;61:1879-80.

11. Hannan EL, O'Donnell JF, Kilburn H Jr, Bernard HR, Yazici A Investigation of the relationship between volume and mortality for surgical procedures performed in New York State hospitals. JAMA 1989;262:503-10.

12. Paone G, Higgins RS, Spencer T, Silverman NA. Enrollment in the Health Alliance Plan HMO is not an independent risk factor for coronary artery bypass graft surgery. Circulation. 1995;92(Suppl):II69-72.

13. Mauldin PD, Weintraub WS, Becker ER. Predicting hospital costs for first-time coronary artery bypass grafting from preoperative and postoperative variables. Am J Cardiol. 1994;74:772-5.

14. Hannan EL, Kilburn H Jr, Bernard H, O’Donnell JF, Lukacik G, Shields EP. Coronary artery bypass surgery: the relationship between inhospital mortality rate and surgical volume after controlling for risk factors. Med Care. 1991;29:1094-107.

15. Luft HS, Bunker JP, Enthoven AC. Should operations be regionalized? The empirical relation between surgical volume and mortality. $N$ Engl J Med. 1979;301:1364-9.

16. Hannan EL. The relation between volume and outcome in health care. N Engl J Med. 1999;340:1677-9.

17. Clark RE. Outcome as a function of annual coronary artery bypass graft volume. The Ad Hoc Committee on Cardiac Surgery Credentialing of The Society of Thoracic Surgeons. Ann Thorac Surg. 1996;61:21-6.

18. Shroyer ALW, Marshall G, Warner B, Johnson RR, Guo W, Grover FL, et al. No continuous relationship between Veterans Affairs hospital coronary artery bypass grafting surgical volume and operative mortality. Ann Thorac Surg. 1996;61:17-20.

19. Sowden AJ, Deeks JJ, Sheldon TA. Volume and outcome in coronary artery bypass graft surgery: true association or artefact? BMJ. 1995;311:151-5.

20. Sollano JA, Gelijns AC, Moskowitz AJ, Heitjan DF, Cullinane S, Saha $\mathrm{T}$, et al. Volume-outcome relationships in cardiovascular operations: New York State, 1990-1995. J Thorac Cardiovasc Surg. 1999; 117:419-30.

21. Hannan EL, Siu AL, Kumar D, Kilburn H Jr, Chassin MR. The decline in coronary artery bypass graft mortality in New York State: the role of surgeon volume. JAMA. 1995;273:209-13.

22. Early GL, Roberts SR. Excellence and low case volume: an example of the inapplicability of volume-based credentialing. Ann Thorac Surg. 2000;69:146-50.

23. American College of Surgeons Advisory Council for Cardiothoracic Surgery. Guidelines for standards in cardiac surgery (revised 1996). Bull Am Coll Surg. 1997;82:27-9

24. Finkler SA. Cost effectiveness of regionalization: further results for heart surgery. Health Serv Res. 1981;16:325-3.

25. Dudley RA, Harrell FE Jr, Smith LR, Mark DB, Califf RM, Pryor DB, et al. Comparison of analytic models for estimating the effect of clinical factors on the cost of coronary artery bypass graft surgery. J Clin Epidemiol. 1993;46:261-71.

26. Longo KM, Cowen ME, Flaum MA, Valsania P, Schork MA, Wagner LA, et al. Preoperative predictors of cost in Medicare-age patients undergoing coronary artery bypass grafting. Ann Thorac Surg. 1998;66:740-6.

27. Freeman JL, Fetter RB, Park H, Schneider KC, Lichtenstein JL, Hughes JS, et al. Diagnosis-related group refinement with diagnosisand procedure-specific comorbidities and complications. Med Care. 1995;33:806-27.

28. Shwartz M, Young DW, Siegrist R. The ratio of costs to charges: How good a basis for estimating costs? Inquiry. 1995;32:476-81.

29. Warner CD, Weintraub WS, Craver JM, Jones EL, Gott JP, Guyton RA. Effect of cardiac surgery patient characteristics on patient outcomes from 1981 through 1995. Circulation. 1997;96:1575-9.

30. Katz NM, Wolfe-Pearce JL, Chase GA. Comparison of results and risk factors of cardiac surgery in two 3-year time periods in the 1990s. Am J Cardiol. 1998;81:1400-4. 
31. Estafanous FG, Loop FD, Higgins TL, Tekyi-Mensah S, Lytle BW, Cosgrove DM, et al. Increased risk and decreased morbidity of coronary artery bypass grafting between 1986 and 1994. Ann Thorac Surg. 1998;65:383-9.

32. Weintraub WS, Craver JM, Jones EL, Gott JP, Deaton C, Culler SD, et al. Improving cost and outcome of coronary surgery. Circulation. 1998;98(Suppl):II23-8.

33. Weintraub WS, Connolly S, Canup D, Deaton C, Culler S, Becker E. Total hospital cost for coronary revascularization: hospital (UB92) and professional (RBRVS) components. J Am Coll Cardiol. 1998; 31(Suppl):172A-3A.

34. Ferraris VA, Ferraris SP, Singh A. Operative outcome and hospital cost. J Thorac Cardiovasc Surg. 1998;115:593-602.

35. Samuelson PA, Nordhaus WD. Economics. 16th ed. Boston: Irwin McGraw Hill; 1998. p. 115-31

36. Finkler SA, Ward DM. Issues in cost accounting for health care organizations. 2nd ed. Gaithersburg: Aspen Publishers, Inc; 1999. p. 24-36.

37. Rosen AB, Humphries JO, Muhlbaier LH, Kiefe CI, Kresowik T, Peterson ED. Effect of clinical factors on length of stay after coronary artery bypass surgery: results of the Cooperative Cardiovascular Project. Am Heart J. 1999;138(1Pt1):69-77.

38. Iezzoni LI. The risks of risk adjustment. JAMA. 1997;278:1600-7.

39. Hannan EL, Racz MJ, Jollis JG, Peterson ED. Using Medicare claims data to assess provider quality for CABG surgery: Does it work well enough? Health Serv Res. 1997;31:659-78.

40. Hartz AJ, Kuhn EM. Comparing hospitals that perform coronary artery bypass surgery: the effect of outcome measures and data sources. Am J Public Health. 1994;84:1609-14.

41. Landon B, Iezzoni LI, Ash AS, Shwartz M, Daley J, Hughes JS, et al. Judging hospitals by severity-adjusted mortality rates: the case of CABG surgery. Inquiry. 1996;33:155-66.

\section{Discussion}

Dr Timothy J. Gardner (Philadelphia, Pa). This report by Dr Shahian and associates on the relationship between CABG case volume and direct costs incurred was very well done and is quite timely. At a recent meeting with the physician director of Medicare's Center for Health Plans and Providers, we were told once again about the continued interest of the Health Care Financing Administration (HCFA) in establishing "centers of excellence" for, among other things, CABG. In HCFA's original proposal for such centers, the assumption was made that concentrating clinical volume for $\mathrm{CABG}$ and other high-volume procedures at several rather than multiple sites will result in improved quality outcomes and cost savings. This study is an important demonstration that this assumption does not necessarily hold, at least within a certain range.

I have a couple of observations for which I would appreciate Dr Shahian's responses. First, the smallest of these 12 hospitals in the present report had 220 acute care beds, and the fewest number of CABG cases done annually in any of the hospitals was 271. Assuming that at least $15 \%$ to $30 \%$ more major cardiac cases were done in each of these 12 hospitals, none represents a truly low volume center. At the time of the study, Massachusetts had and still maintains, I believe, limited availability to cardiac surgery as a state health policy, and the ratio of cardiac surgery units to population size continues to be low in comparison with other regions in the country. The same situation exists in New York State, where clinical outcomes have been reported to have improved substantially during the past decade, erasing the original discrepancy identified in quality out- comes observed between high and low volume programs. There are, however, a number of areas in the United States where CABG is being done in much smaller hospitals and where the surgical numbers are considerably below those seen in even the lowest volume Massachusetts hospital.

In the April 18 issue of Circulation, a study from Washington University concluded that from 1984 to 1996, differences in angioplasty-related mortality between high and low volume hospitals have narrowed significantly but have not been eliminated. Between 1993 and 1996, the mortality rate dropped from $2.5 \%$ to $1.7 \%$ in low volume hospitals, that is, those performing fewer than 200 angioplasties a year, compared with a steady mortality rate of $1.3 \%$ for higher volume institutions. I would ask Dr Shahian to comment on whether he thinks there is a floor in CABG activity below which quality and cost effectiveness may be threatened.

Dr Shahian, you state in your paper that some small but highquality, well-organized cardiac surgical programs may function with equal or greater efficiency than very large programs and that the number of surgeons and other personnel is more manageable, which may permit greater standardization of care. I think you have thrown down the gauntlet to some of the larger programs. In addition, your data showed that programs in which residents are trained are more costly.

Do you think that the same well-functioning organization can be achieved in programs of such small size that the surgeons have to operate at two or more hospitals and where small cardiac surgical groups are required to be responsive and available at several sites simultaneously? I feel certain that there are some logistic challenges that even the most skilled cardiac surgeons cannot cope with adequately under these circumstances, and I am sure there are some situations in which volume does affect cost and quality. I would also comment that your cost analysis is based on direct costs and not the associated indirect expenses that are needed to maintain a cardiac surgery program in small hospitals that have to expend quite a bit of money in starting up these programs.

Finally, you noted that Medicare patients, female patients, those operated on in hospitals with residency programs, and those with higher clinical acuity classes, as reflected by the refined DRG classification, had hospitalizations associated with higher direct costs. On the other hand, among the continuous variables of age, size of the hospitals, and clinical case volume, there was no relationship with the direct costs. How is it that Medicare patients, most of whom were 65 years or older, were noted to have greater associated direct costs while this relationship was not seen when the ages of the patients were analyzed?

Dr Shahian. You raise a very interesting point. In this paper we did not address the lower limit or threshold level for cost-effective functioning. I think it is a good statistical principle not to extrapolate the findings of a model beyond the range of the data set from which the model was estimated. Thus, I would not want to say that these findings could be extrapolated to a hospital doing 100 cases a year, since no such programs were studied. I would not necessarily even extrapolate these findings to other procedures in cardiac surgery, and certainly not to other surgical specialties.

This study dealt with a mature procedure with which we all have considerable experience. It may not be applicable to other less mature and standardized procedures practiced by less experienced 
surgeons. Our result may not be applicable to other states having a much greater variability in the size of the programs and the number of cases done. Such caveats notwithstanding, these observations were made within a state with a broad range of programs that I suspect are representative of a large majority of the programs in the country.

With respect to the issue of using direct versus total cost, we actually did the analysis for each and the results were comparable. The reason we focused on direct costs is that the methods of determining indirect costs vary tremendously between hospitals, and we thought that direct costs were a better estimate of the true costs associated with the procedure.

Dr Gregory L. Kay (Los Angeles, Calif). I have a different perspective about volume. In California, we have 125 hospitals offering cardiac surgery services. Over $60 \%$ of these do fewer than 250 cardiac procedures, with more than $50 \%$ performing fewer than 200 cases a year. These are true "low volume" programs. Didn't you actually study what we would consider to be "medium volume" programs, which probably accounts for your results?

Dr Shahian. I agree completely, and I state clearly in the paper that there were no very low volume programs. I also believe that the case volumes represented in this study reflect the experience in a vast majority of the programs across the country, with the exception of states like California, where deregulation has led to a proliferation of very low volume programs.
Dr Francis Robicsek (Charlotte, $N C$ ). Just like this study, in our study of several hospitals, we also found very poor correlation between average cost and hospital size. We could really identify only one statistically significant factor that influenced the cost, that is, the rate of postoperative complications. It was evident that while in the individual patient the chance of complications was directly related to preoperative risk factors, in different programs the rate of postoperative complications and costs varied widely despite the fact that the preoperative patient clinical features of their populations were comparable.

In other words, while most if not all programs, regardless of their size, may function with few complications and low costs in lowrisk patients, only programs with clinical excellence may do the same in high-risk patients. To lower the costs, one may do one of two things: either get rid of the poor-risk patient or get rid of the bad surgeon.

Dr Shahian. Thank you. I agree with your comments, but I would emphasize that the surgeon with the lowest morbidity and mortality may be at either a large or a small hospital. Furthermore, other factors are critical in addition to the surgeon. The process and flow of cardiac surgery in an institution, the overall coordination of care, and the other members of the team are equally important. I do not think that these factors are related to hospital size. Every hospital, large and small, should strive to improve the efficiency of operation. 